\title{
DEFORESTATION MONITORING IN DIFFERENT BRAZILIAN BIOMES: CHALLENGES AND LESSONS
}

\author{
C. A. Almeida ${ }^{1, *}$, D. M. Valeriano ${ }^{1}$, L. Maurano ${ }^{1}$, L. Vinhas ${ }^{1}$, L. M. G. Fonseca ${ }^{1}$, D. Silva ${ }^{1}$, C. P. F. Santos ${ }^{2}$, F. S. R. V.

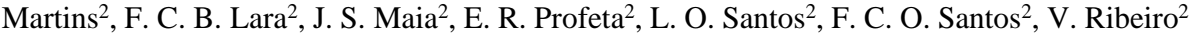 \\ ${ }^{1}$ National Institute for Space Research - INPE, São José dos Campos, Brazil - (claudio.almeida, lubia.vinhas, \\ leila.fonseca, daniel.silva, dalton.valeriano)@inpe.br \\ ${ }^{2}$ Foundation for Science, Technology and Space Applications - FUNCATE, São José dos Campos, Brazil - (cferri, \\ flora.martins, ferbaruel, janaina.maia, ederson.profeta, leonardo.santos, fabiana.santos, vanildes.ribeiro)@ funcate.org.br
}

KEY WORDS: Deforestation monitoring, REDD+, Amazon, Cerrado, Atlantic Forest, Caatinga, Pampa, Pantanal

\begin{abstract}
:
Monitoring the conversion of native vegetation has challenged Brazilian government and scientists since the 1980s. In the case of the Amazonian forests, the Amazon Gross Deforestation Monitoring Project - PRODES has developed an effective methodology that provides consistent annual data on deforestation areas on a scale of 1:250,000, since 1988. In this article, we present some aspects of the evolution of this methodology, the key processes to produce accurate deforestation maps during the last 30 years and the new challenges that the Project would face. A central lesson is that no computational technique has, to date, been able to achieve the quality of deforestation maps produced by visual interpretation of satellite images and manual mapping.
\end{abstract}

\section{INTRODUCTION}

\subsection{Context}

Territorial management aligned with sustainable development depends, among others, on reliable primary land cover data. Since Brazil has an extensive territory of more than 8.5 million square kilometers, any mapping process requires consistent human resources and planning efforts. With the wide range of remote sensing products, the perception of useful data availability for decision making can be misleading. Given this reality, the Ministry of the Environment established the "Brazilian Biomes Environmental Monitoring Program" to ensure greater efficiency on the monitoring of deforestation, land cover and land use, selective logging, fire occurrence and recovery of native vegetation (MMA, Ordinance no. 365/2015). Considering the benchmark achievements excellence of the Amazonian Gross Deforestation Monitoring Project - PRODES, the methodological approach developed by INPE and operated by FUNCATE was borrowed to design the expansion of monitoring throughout the whole Brazilian territory. The scope of this national monitoring system represents a challenge considering the large volume of data to be produced and the discrepancies in vegetation and land use characteristics between each biome. In this work we present the evolution of the monitoring system developed by INPE under the General Coordination of Earth Observation.

\section{EVOLUTION OF INPE'S DEFORESTATION MONITORING SYSTEM}

\subsection{0 years of Amazonian Gross Deforestation Monitoring Project - PRODES}

PRODES begins in 1988 to face the challenge of mapping deforestation over printed Landsat images at 1:250,000 scale, with a minimum mapping unit set at 6.25 ha (1 square millimeter on paper) across the Legal Amazon, a region that encompasses $61 \%$ of the Brazilian territory. Mapping activities focused on primary forest vegetation within the Legal Amazon, where the accumulated gross deforestation, closed to $300,000 \mathrm{~km}^{2}$ by 1980 , reached $788,000 \mathrm{~km}^{2}$ in 2018 .

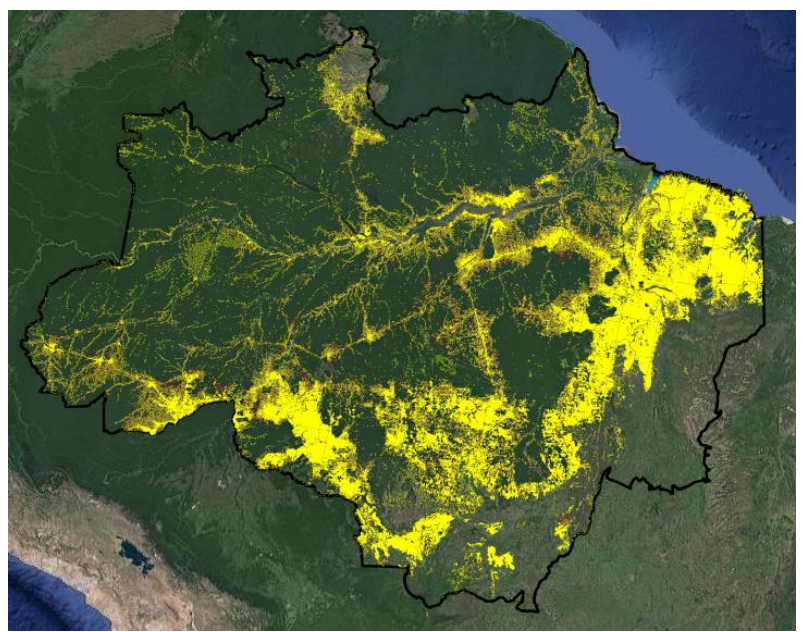

Figure 1. Removal of primary forest vegetation in the Legal Amazon (yellow polygons) until 2018 according to PRODES in 30 years of data production. Source: Terrabrasilis (http://terrabrasilis.dpi.inpe.br)

Increased INPE's computing capability combined to research and innovation in the field of remote sensing allowed the transition between the initial analogic system ("Analog PRODES"), that operated from 1988 to 2002, to a digital based system, called "PRODES Digital Project" (Moreira et al., 2003; Valeriano et al., 2014). Since the internet became available to the general public, INPE provides the deforestation maps in vector format, as well as all the satellite images of Digital PRODES, ensuring full transparency of its methodology and results (Figure 1).

\footnotetext{
$1 *$ Corresponding author
} 
The clear-cut deforestation process in the Legal Amazonia changed along these years of monitoring (Figure 2), coinciding with the implementation of government conservation policies. Large clearings progressively represented smaller amounts of total annual deforestation (Rosa et al., 2012). However, the recent increase in deforestation rate has also shown an increase in large polygons. The improvement in spatial resolution of remote sensing products used in PRODES might be used to face the challenge of detecting small areas of vegetation removal.

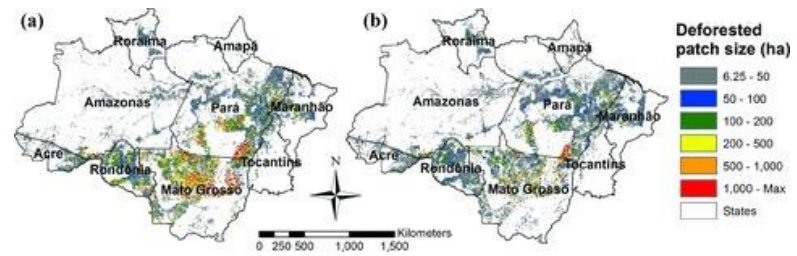

Figure 2. Distribution of deforested patches of different sizes in the Brazilian Amazon for periods of (a) rapidly increasing deforestation (2002 through 2004) and (b) rapidly decreasing deforestation (2005 through 2009). Reprinted from Rose et al., 2012.

This complete, consistent and transparent system consolidated Brazil as a benchmark in land cover monitoring. PRODES resulting data and intelligence on the dynamics of deforestation were crucial to the implementation of the "Action Plan for the Prevention and Control of Deforestation in the Legal Amazonia" (PPCDAm) in 2004 by the Federal Government. The Action Plan aims to constantly and consistently reduce the annual deforestation rate in Amazon (Figure 3). The success of the policies and implementation of deforestation monitoring and control programs in the Amazon Biome allowed Brazil to request for results-based payments for deforestation and forest degradation reduction (REDD+, MMA Ordinance No. 41/2014) under the United Nations Framework Convention on Climate Change (UNFCCC). On the other hand, land cover monitoring in the rest of the territory remained limited. It was natural to expand the system to the other biomes starting with the Cerrado, as the most extent biome after the Amazon, representing together approximately $75 \%$ of the national territory.

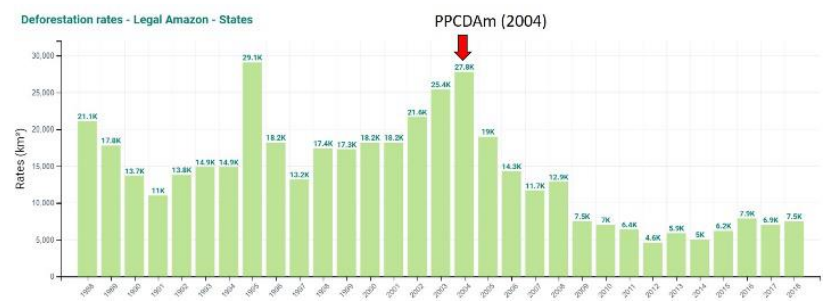

Figure 3. Deforestation rates ( $\left.\mathrm{km}^{2} / \mathrm{year}\right)$ in the Legal Amazon between 1988 and 2018 and the visible success in curbing forest loss after PPCDAm creation. Source: Edited from Terrabrasilis (http://terrabrasilis.dpi.inpe.br).

\subsection{Cerrado: expanding the system to non-forest physiognomies}

Cerrado (Brazilian savanna) covers nearly 2 millions square kilometers, or $25 \%$ of the country. The region is listed as one of the priority biodiversity hotspots in the world (Myers et al., 2000). Almost $50 \%$ of the original Cerrado has been cleared by deforestation (http://terrabrasilis.dpi.inpe.br). The Cerrado vegetation is composed by forest, savanna and grassland phytophysiognomies (Ribeiro and Walter, 2008). Different from the Legal Amazon monitoring, the definition of deforestation adopted by the National Policy on Climate Change and the Plan for Prevention and Control of Deforestation and Forest Fires in the Cerrado (PPCerrado, for the acronym in Portuguese) refers to the conversion of natural areas into other land-use categories, not only forest conversion.

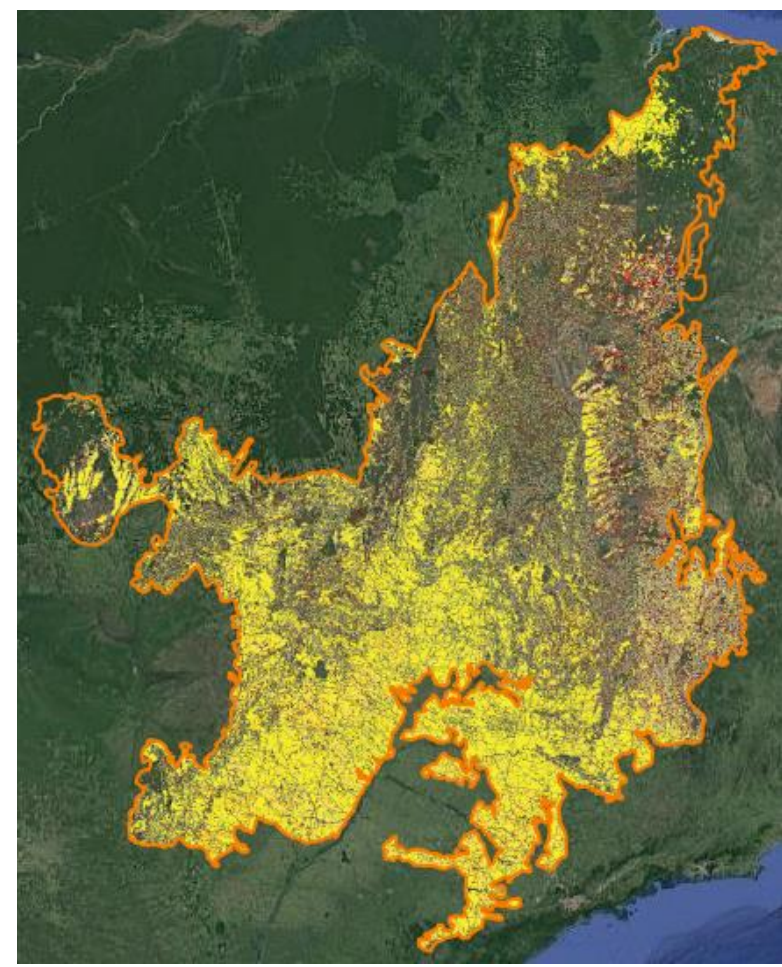

Figure 4. Deforested area until 2018 (yellow polygons) in the Cerrado (orange line) Source: Terrabrasilis (http://terrabrasilis.dpi.inpe.br).

The National Policy on Climate Change (Law No. 12,187/2009), establishes, among the mitigation activities planned up to 2020 , the objective of a $40 \%$ reduction in deforestation in the Cerrado biome compared to the average annual deforestation observed between 2002 and 2008. Considering the lack of historical data collection, one of the initiatives implemented in Brazil was the Brazil-Germany cooperation project "Prevention, control and monitoring of irregular burning and forest fires in the Cerrado", known as the Cerrado-Jalapão Project. The aim was to promote the development of methodologies to detect and quantify burned areas in the Cerrado Biome and to establish the reference level of greenhouse gas emissions from deforestation, based on the construction of a historical biennial series of deforestation maps from 2000 to 2013.

To enable continued monitoring of the Cerrado, resources had to be sought from the World Bank. This allowed the execution of two projects: "Mapping and Estimation of $\mathrm{CO} 2$ Emissions from Deforestation in the Cerrado Biome for the Years 2012 and 2014" and "Thematic mapping of deforestation in Digital Format for the Cerrado biome in scale of 1: 250,000 for the period 2013-2015". For the period 2016 to 2019 , the monitoring is granted by the World Bank and supported by the Forest Investment Program (FIP) through the "Forest Fire Prevention Systems and Vegetation Coverage Monitoring in the Brazilian Cerrado". 


\subsection{Completing the frame: Atlantic Forest, Caatinga, Pampa and Pantanal}

The total extent of Atlantic Forest, Caatinga, Pampa e Pantanal biomes in Brazil reaches 2,2 million square kilometers ( 25\% of the national territory). Mapping and monitoring initiatives have been undertaken to provide to the government reliable data on remaining vegetation cover of these biomes. Two projects have been conducted for this purpose at a national scale by the Ministry of the Environment (MMA): the "Project for the Conservation and Sustainable Use of Brazilian Biological Diversity" (PROBIO) and the subsequent "Project of Satellite Deforestation Monitoring of the Brazilian Biomes" (PMDBBS). However, the initiatives were discontinued. More recently, the "Brazilian Biomes Environmental Monitoring Program" started to ensure greater efficiency on the monitoring deforestation, land cover and land use, selective logging, fire occurrence and recovery of native vegetation (MMA, Ordinance no. 365/2015). In this scenario, MMA, INPE and FUNCATE sought financial support from the Amazon Fund, giving rise to the "Environmental Monitoring of Brazilian Biomes" Project (http://www.fundoamazonia.gov.br/en/projeto/EnvironmentalMonitoring-of-Brazilian-Biomes/).

\section{METHODOLOGICAL APPROACH}

\subsection{A simple and efficient protocol for clear-cut deforestation monitoring}

The PRODES Project uses multispectral and medium resolution satellite products (10 to 30 meters), mainly Landsat- 8 , Sentinel2 and CBERS-4 images, for visual interpretation and manual mapping. The clear-cut detection is based on the analysis of spatial and temporal changes in vegetation cover. Six main features are used in the scene classification: color, shape, shadow, texture, color tonality and context. The last criterion is the most complex because it is composed by both spatial and temporal descriptors, like the distribution of neighborhood deforestation processes or land use practices type, frequency and intensity. The whole processes of deforestation detection and mapping are conducted in the multiusers software TerraAmazon, developed by INPE with strict control for access, project and concurrent use between users (Figure 5).

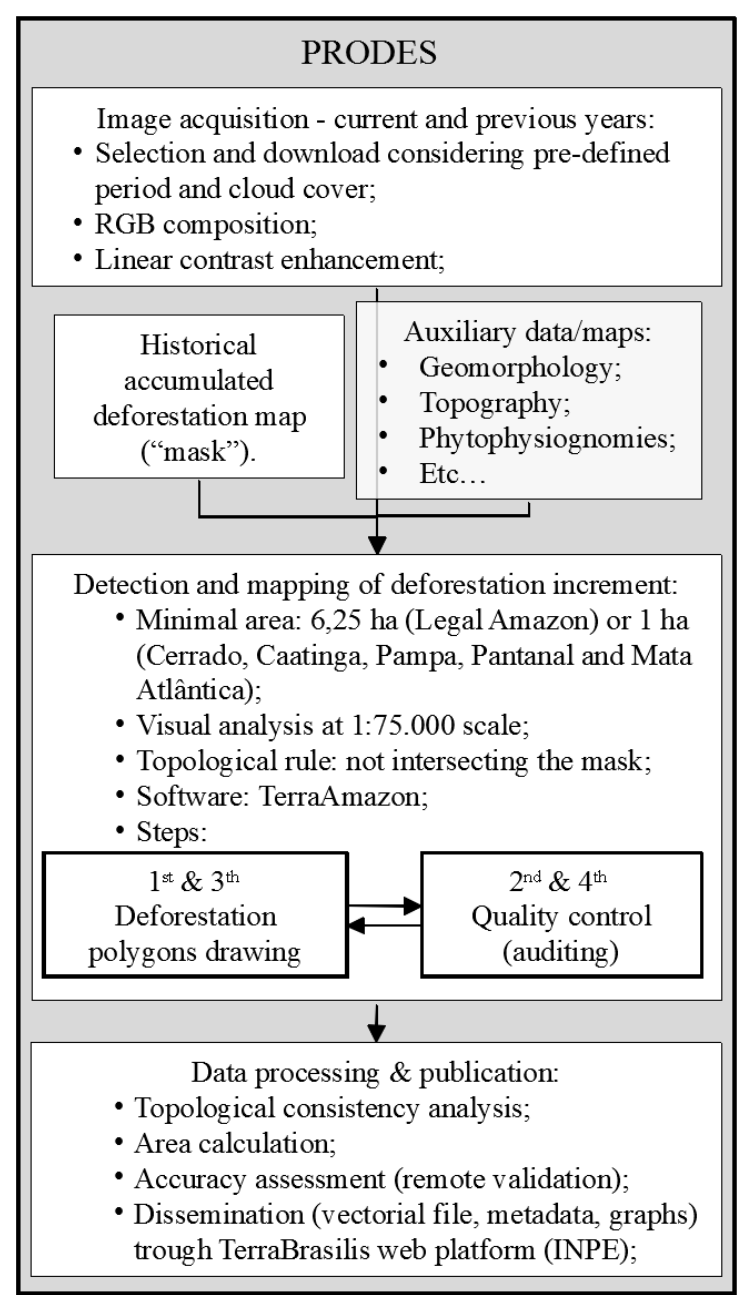

Figure 5. Pictorial representation of the PRODES methodology.

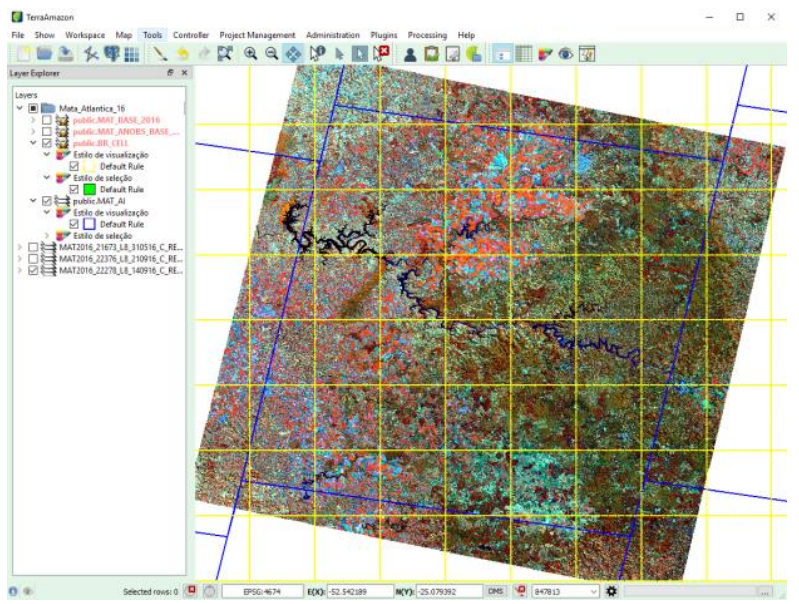

Figure 6. TerraAmazon workspace. Interpreters work within a cell grid (yellow lines), editing only one satellite image cell at a time. Image limits are defined by another grid (blue grid) - in this case Path/Row 222/78 of Landsat-8 OLI (-26.106634; $51.817383)$ 


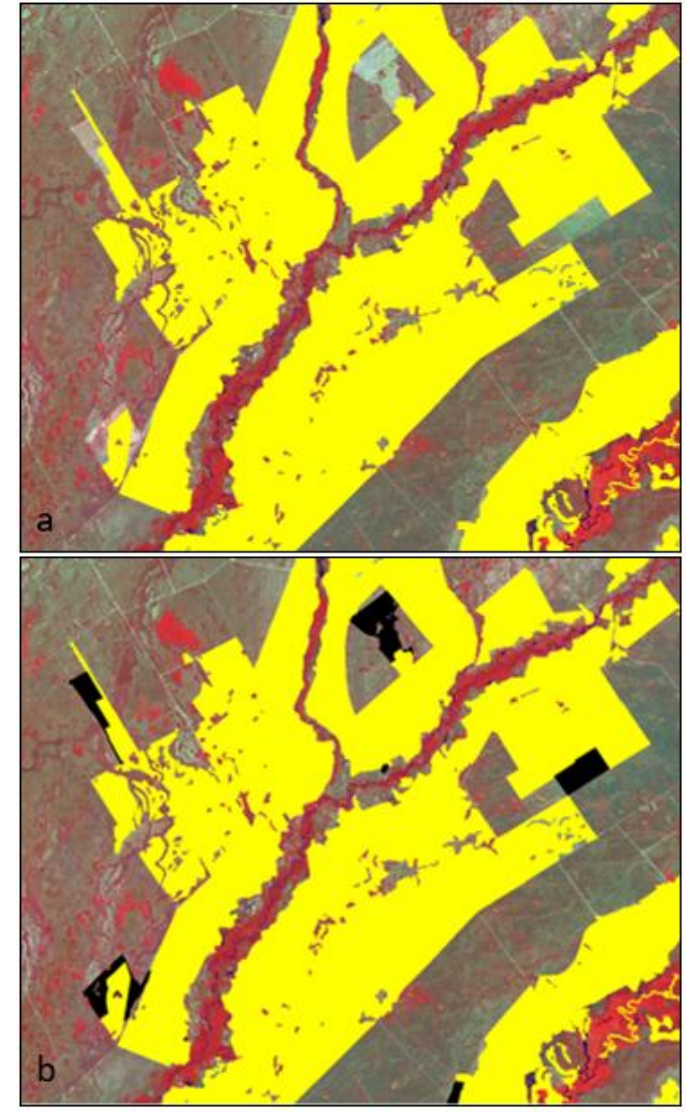

Figure 6. Deforestation mask (yellow polygons - a, b) and deforestation increments detected in the Pantanal in 2019 (black polygons $(-17.145629 ;-55.325931)$.

\subsection{Challenges in detecting and mapping native vegetation removal in non-Amazonian Brazilian biomes}

Biological characteristics, climate and land use practices of each phytophysiognomy can alter the precision of vegetation mapping. Hereafter, we summarize some challenges for monitoring deforestation through optical remote sensing imagery in non-Amazonian biomes.

\section{- Cerrado:}

- Species traits associated with seasonality (i.e.: deciduous canopies);

- Important gradient of vegetation density which implies greater soil participation in the spectral response (Figure7);

- Fire occurrence not always related to deforestation;

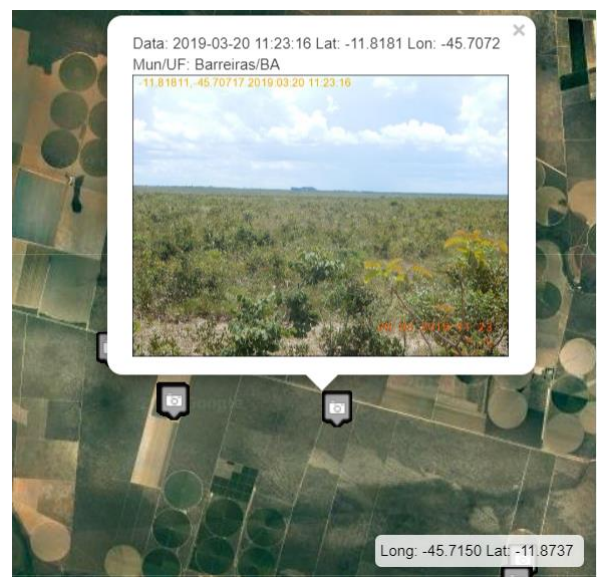

Figure 7. An example of Cerrado vegetation observation: field photography and high resolution image from GoogleEarth. Interpreters need to be well trained in the analysis of non-forest phytophysiognomies.

(http://www.dpi.inpe.br/fototeca/fototeca.html)

\section{- Caatinga:}

- Species traits associated with seasonality (i.e.: deciduous canopies);

- Management practices: clear cut not necessarily resulting from land cover change (for firewood production);

- Low density vegetation with sandy soil exposure affecting the albedo;

- Important gradient of vegetation density implying greater soil participation in the spectral response (Figure 8);

- Degradation by severe droughts periods like El Niño occurrences between 2011 and 2016;

- Cloud cover in the North-East region;

- Fire occurrence not always related to deforestation;
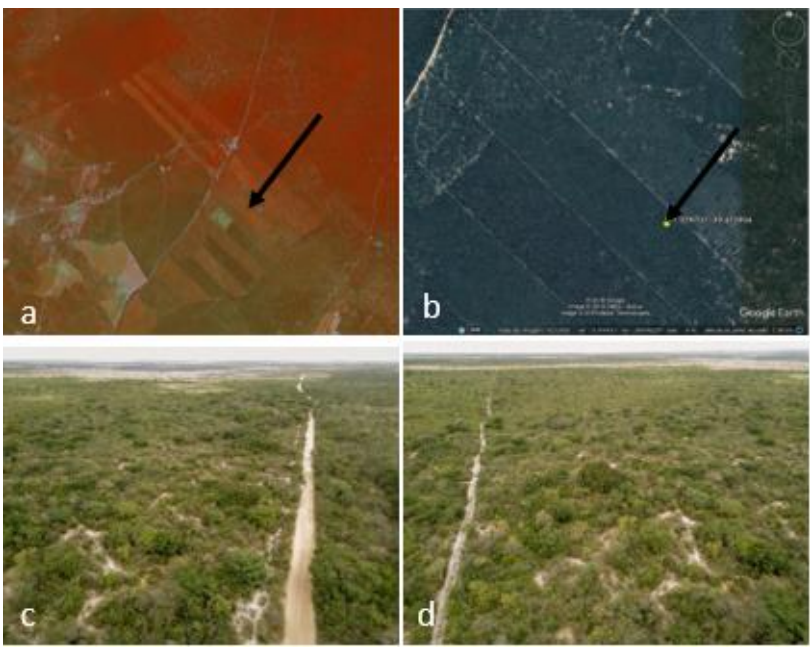

Figure 8. An example of Caatinga native vegetation with some degree of anthropogenic impact according to Landsat image (a) and high-resolution image from GoogleEarth ${ }^{\circledR}(b)$, but not converted to other land cover as observed in field photography (c, d).

- Atlantic Forest:

- Fragmentation of remaining native vegetation;

- Tiny dimensions and irregular formats of the clearings;

- Cloud cover in the northern region;

- Shading caused by the relief, especially in winter;

- Pantanal (Figure 9):

- Floodplain dynamics, where bare soil is frequently observed

- Similarity between natural pasture (sometimes under continuous grazing) and exotic planted pasture (Brachiaria sp.); - Management of natural pasture, with selective removal of shrub vegetation, resulting in a misleading aspect in satellite images;

- Fire occurrence not always related to deforestation;

- Rapid apparent regeneration of native grassland vegetation in fallow areas; 


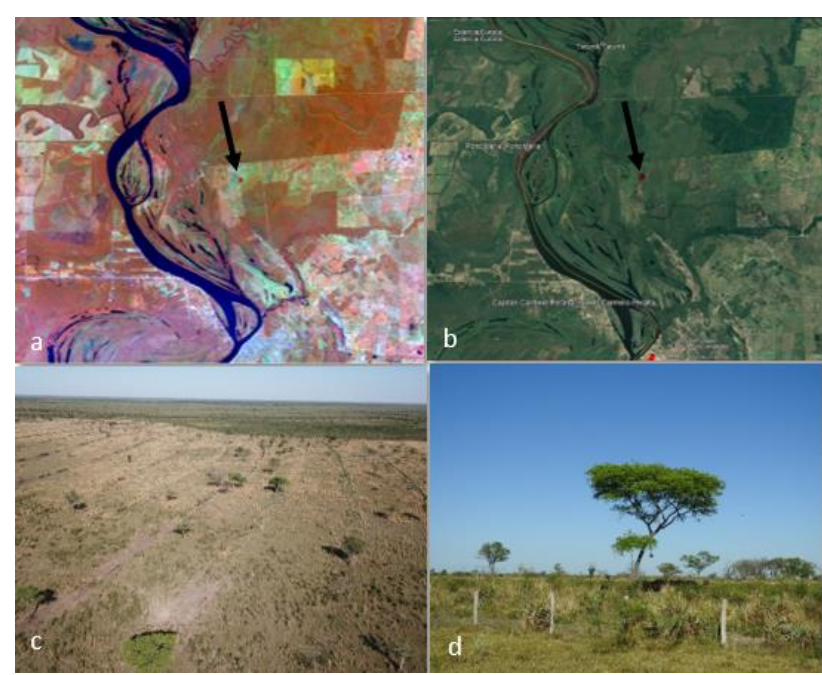

Figure 9. Deforested area of Pantanal in (a) a Landsat image (2019), which was confirmed by a field campaign (c, d). High resolution images from GoogleEarth ${ }^{\circledR}$ (b) contributed to the mapping process.

- Pampa (Figure 10):

- Management of natural pasture, with selective removal of shrub vegetation (Baccharis dracunculifolia DC - local name "vassoura" and Senecio brasiliensis (Spreng.) Less. - local name "maria-mole"), resulting in a misleading aspect in satellite images;

- Similarity between natural pastures (sometimes under continuous grazing) and exotic invasive Eragrostis plana Nees ("capim-annoni");

- Areas with commercial tree plantations of mixed exotic and native forests;

- Ecotone areas where native forest is replaced by natural grassland;

- Rapid apparent regeneration of native grassland vegetation in fallow areas;

- Shallow soils and rocky outcrops affecting the albedo;
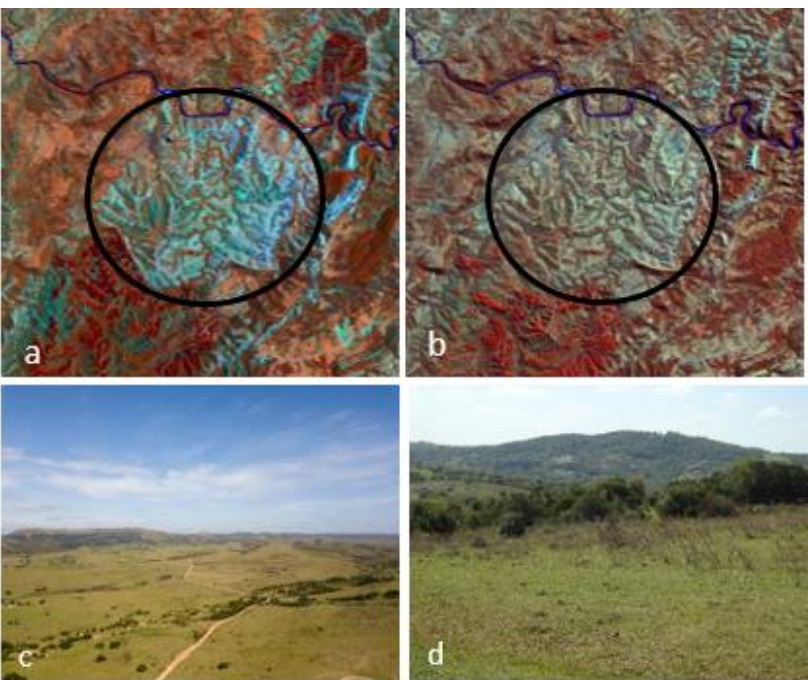

Figure 10. Example of native grassland management for cattle at Pampa - Landsat/OLI image in 2016 (a) and 2019 (b) and (c, d) photography during field campaign in 2019 (-31.028979; 53.332198)

A common challenge among biomes in vegetation mapping is to provide accurate original vegetation maps and to correctly discriminate forest and non-forest phytophysiognomies. A lack of such products at a consistent spatial scale might compromise vegetation monitoring as all subsequent maps of native vegetation removal would depend on.

\subsection{Lessons learned}

A central lesson of more than 30 years of PRODES Project, is that no computational technique has given more accurate deforestation maps than those produced by visual interpretation of satellite images and manual mapping. This emphasizes the importance of the interpreter's analysis and decision making, achieved through its knowledge about land use dynamics, especially agricultural cycles and forest/non-forest natural land management and also field experience. The availability of consistent temporal images series significantly influences the detection of temporal changes in land cover. Auxiliary data, such as spectral mixture model and spectral index, may help to improve the mapping process. However, temporal analysis of the color composition should remain the main source of information. Another crucial point to produce accurate maps refers to the implementation of diversified quality control processes, like methodological transparency and simplicity, field campaigns, extensive auditing, free access to the data and independent validation.

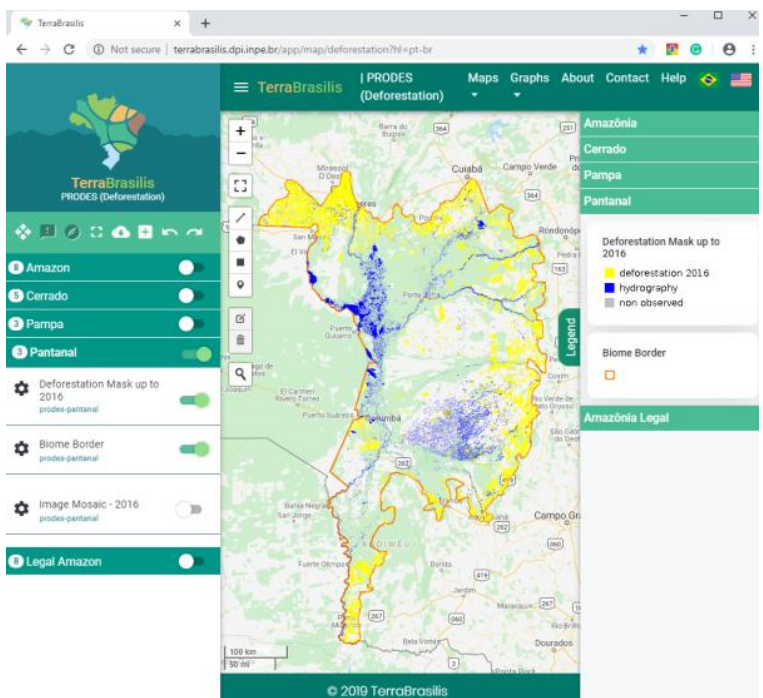

Figure 11. TerraBrasilis web platform developed by INPE for dissemination of deforestation monitoring data. Available at http://terrabrasilis.dpi.inpe.br/

\section{LOOKING FORWARDS}

As stated on the Amazonian FREL submission (MMA, 2018), "the consistency of the PRODES time series is ensured by using the same deforestation definition, same minimum mapping area, similar satellite spatial resolution, same Forest/Non Forest vegetation boundaries, and same methodological approach to analyze the remotely sensed data at every new assessment". However, the paradigm of the exponential increase in remote sensing data availability (Hansen and Loveland, 2012) and the increase in low cost computing power justify to investigate new automatic techniques for mapping vegetation.

Moreover, today it is possible to store, access, process and analyse remote sensing data in a unique platform, like Google Earth Engine (GEE) (Gorelick et al., 2017) and Open Data Cube (ODC) (Lewis et al., 2017). Such tools could allow to fill in the 
gap between the increase in remote sensing data production and the mapping cost in time.

\section{CONCLUSIONS}

Despite the large extent of Brazilian territory and the high diversity in phytophysiognomies, that both difficult deforestation monitoring, the high accuracy of vegetation removal maps produced by the PRODES Project is affordable. Today, the average operational cost for annual deforestation monitoring in the whole Brazilian territory doesn't reach US\$ 0,16 per square kilometer, and falls to less than US\$ 0,04 in Brazilian Amazon. However, new challenges need to be faced by using new data and mapping methodologies, but preserving and exploiting the knowhow acquired during more than 30 years of deforestation monitoring in Brazil.

\section{ACKNOWLEDGEMENTS}

We are grateful to the Amazon Fund, the World Bank, the MMA and the National Council for Scientific and Technological Development $(\mathrm{CNPq})$ that currently grant the deforestation monitoring projects for all Brazilian Biomes, and that provide financial and logistical support for this article. We acknowledge the INPE and FUNCATE, principally all technical teams of the different projects, for the construction of PRODES methodology and its operation during the last decades. Finally, we are grateful to the organizing committee of the LAGIRS 2020: 2020 Latin American GRSS \& ISPRS Remote Sensing Conference for the opportunity to present some lessons of 30 years of deforestation monitoring in Brazil.

\section{REFERENCES}

Gorelick, N., Hancher, M., Dixon, M., Ilyushchenko, S., Thau, D., Moore, R., 2017. Google Earth Engine: Planetary-Scale Geospatial Analysis for Everyone. Remote Sensing of Environment, 202, 18-27.

Hansen, M. C., Loveland, T. R., 2012. A Review of Large Area Monitoring of Land Cover Change Using Landsat Data. Remote Sensing of Environment, 122, 66-74.

Lewis, A., Oliver, S., Lymburner, L., Evans, B., Wyborn, L., Mueller, N., Raevksi, G. et al., 2017. The Australian Geoscience Data Cube - Foundations and Lessons Learned. Remote Sensing of Environment, 202, 276-92.

MMA (Brazilian Ministry of Environment), 2018. Brazil's submission of a Forest Reference Emission Level (FREL) for reducing emissions from deforestation in the Amazonia biome for REDD+ results-based payments under the UNFCCC from 2016 to 2020, MMA, http://redd.mma.gov.br/.

Moreira, J. C., Mello, E. M. K., Santos J. R. dos, Shimabukuro Y. E., Duarte V., Souza, M. I., Barbosa C. C., Souza R. C. M. de, Paiva J. A. C. Sistema de Informações Georreferenciadas do Desflorestamento da Amazônia. GISBRASIL 2003, São PauloSP, 2003.

Myers, N., Mittermeier, R., Mittermeier, C. et al., 2000. Biodiversity hotspots for conservation priorities. Nature, 403, 853-858.

National Institute for Space Research. Earth Observation General Coordination. TerraBrasilis. Available at http://terrabrasilis.dpi.inpe.br/. Accessed: November 13, 2019.
National Institute for Space Research. Earth Observation General Coordination. Monitoring Program of the Amazon and Other Biomes. Deforestation - Legal Amazon - Available at http://terrabrasilis.dpi.inpe.br/downloads/. Accessed: November 13,2019

National Institute for Space Research. Earth Observation General Coordination. Monitoring Program of the Amazon and Other Biomes. Deforestation - Cerrado - Available at http://terrabrasilis.dpi.inpe.br/downloads/. Accessed: November 13,2019

Ribeiro, J., Walter, B., 2008. As principais fitofisionomias do bioma Cerrado. In book: Cerrado: ecologia e flora. First edition. Embrapa Cerrados/Embrapa Informação Tecnológica, pp.151212.

Rosa, I., Souza, C., Ewers, R., 2012. Changes in Size of Deforested Patches in the Brazilian Amazon. Conservation biology, 26, 932-937.

Valeriano, D.M., Mello, E.M.K., Moreira, J.C., Shimabukuro, Y.E., Duarte, V., 2004. Monitoring tropical forest from space: the PRODES Digital Project. International Archives of Photogrammetry Remote Sensing and Spatial Information Sciences, 35, 272-274. 